\title{
Microalbuminuria in non-insulin-dependent diabetes: its prevalence in Indian compared with Europid patients
}

\author{
J ALLAWI, P V RAO, R GILBERT, G SCOTT, R J JARRETT, H KEEN, \\ G C VIBERTI, H M MATHER
}

\begin{abstract}
Non-insulin-dependent diabetes mellitus is strikingly common in British Indians, but their susceptibility to diabetic complications is unknown. The ratio of albumin to creatinine concentrations was measured in samples of the first urine voided in the morning in 154 Indian and 82 Europid patients with non-insulin-dependent diabetes and in a control group of 129 non-diabetic Indians. The ratio was significantly higher in the Indian patients than in the Europid patients and the Indian controls. There were no significant correlations between the logarithm of the albumin: creatinine ratio and age, known duration of diabetes, haemoglobin $A_{1}$ concentration, or body mass index within either diabetic group. Hypertension and raised albumin:creatinine ratio were significantly associated, and significant correlations were seen between the logarithm of the albumin:creatinine ratio and systolic and diastolic blood pressures in the Indian but not the Europid diabetics.

Because of the high prevalence of diabetes at a relatively early age in Indians, nephropathy may emerge as an important clinical problem.
\end{abstract}

\section{Introduction}

Non-insulin-dependent diabetes diagnosed fairly early in middle age is strikingly common in the Indian community in Britain. In the Southall diabetes survey the prevalence of known diabetes in Indian subjects aged 40-64 was five to seven times greater than that in comparable Europeans. ${ }^{1}$ The early appearance of the disease and its high prevalence raise important questions about the consequences in terms of morbidity.

Few data have been reported on the susceptibility of Indian diabetics to the complications of the disease. In a preliminary clinical study Indian diabetics were found to have the same crude prevalence of retinopathy and symptomatic ischaemic heart disease as European patients, despite their younger mean age and shorter mean known duration of diabetes. ${ }^{2}$ Clinical (Albustix positive) proteinuria was significantly more common in Indians than Europeans attending a diabetic clinic in Leicester. ${ }^{3}$ These patients included both those with insulin dependent and those with noninsulin-dependent diabetes. Urinary albumin excretion rates that exceed normal values but fall short of clinical proteinuria, as indicated by semiquantitative tests such as Albustix, strongly

Unit for Metabolic Medicine, Guy's Hospital, and Division of Community Medicine, United Medical and Dental Schools (Guy's Campus), London SE1 9RT

J ALLAWI, MB, CHB, research registrar

R GILBERT, MB, MRACP, registrar in endocrinology

G SCOTT, CBIOL, MIBIOL, laboratory technologist

R J JARRETT, MD, FFCM, professor of clinical epidemiology

H KEEN, MD, FRCP, professor of human metabolism

G C VIBERTI, MD, MRCP, senior lecturer in medicine

Ealing Hospital, Southall, Middlesex UB1 3HW

P V RAO, MD, research registrar

H M MATHER, MD, MRCP, consultant physician

Correspondence to: Professor Jarrett. predict clinical nephropathy in insulin dependent diabetics ${ }^{46}$ and increased mortality and morbidity in non-insulin-dependent diabetics. $^{78}$

We compared albumin excretion in Indian patients with noninsulin-dependent diabetes mellitus who were attending a diabetic clinic in Southall with that in a reference group of non-diabetic Indians and that in a group of patients of European origin (Europids ${ }^{9}$ ) with non-insulin-dependent diabetes mellitus who were attending the diabetic clinic at Guy's Hospital.

\section{Subjects and methods}

SUBJECTS

All 305 Indian patients aged between 20 and 65 who were due to attend the diabetic clinic at Ealing Hospital over 10 months were asked by letter to participate in the study. Two hundred and thirty seven patients attended and were initially studied. Of those who did not attend, 15 had moved and could not be traced. The response rate was thus $82 \%$ (237/290). Subsequently, 67 patients receiving insulin treatment were excluded. Thirteen patients found to have urinary tract infections on examination of midstream urine specimens and three whose urine samples were lost were excluded. Thus 154 patients were included in the study.

Details of patients with non-insulin-dependent diabetes and control subjects

\begin{tabular}{|c|c|c|c|}
\hline & \multicolumn{2}{|c|}{ Patients } & \multirow[b]{2}{*}{$\begin{array}{l}\text { Controls } \\
(n=129)\end{array}$} \\
\hline & $\begin{array}{c}\text { Indian } \\
\text { diabetics } \\
(n=154)\end{array}$ & $\begin{array}{l}\text { Europid } \\
\text { diabetics } \\
(n=82)\end{array}$ & \\
\hline $\operatorname{Sex}(M: F)$ & $93: 61$ & $52: 30$ & $57: 73$ \\
\hline Mean age (range) (years) & $50 \cdot 6(28-65)$ & $57 \cdot 2(27-65)$ & $44 \cdot 0(36-55)$ \\
\hline Median known duration of diabetes & $3(0-22)$ & $5(1-19)$ & \\
\hline \multicolumn{3}{|l|}{ No $(\%)$ receiving oral hypoglycaemic } & \\
\hline Mean (SD) haemoglobin $A_{1}(\%)$ & $8 \cdot 9(2 \cdot 4)$ & $8 \cdot 7(1.5)$ & \\
\hline Mean body mass index ${ }^{\star}$ & $27 \cdot 4(4 \cdot 6)$ & $28 \cdot 0(5 \cdot 9)$ & $25 \cdot 5(3 \cdot 6)$ \\
\hline \multicolumn{3}{|l|}{ Mean $(\mathrm{SD})$ blood pressure $(\mathrm{mm} \mathrm{Hg})$ : } & $129 \cdot 8(21 \cdot 9)$ \\
\hline Diastolic & $83.0(10 \cdot 7)$ & $82 \cdot 4(10 \cdot 0)$ & $80 \cdot 1(15 \cdot 0)$ \\
\hline No (\%) with hypertension $\dagger$ & $55(36)$ & $31(38)$ & $32(25)$ \\
\hline \multicolumn{4}{|l|}{ Religion $(\mathrm{No}(\%))$ : } \\
\hline Sikh & $69(45)$ & & $76(59)$ \\
\hline Hindu & $59(38)$ & & $39(30)$ \\
\hline Moslem & $26(17)$ & & $14(11)$ \\
\hline
\end{tabular}

$\star$ Body mass index $=$ weight $(\mathrm{kg})$ over height $(\mathrm{m})^{2}$

†Known or discovered during study.

Eighty two Europid patients attending the diabetic clinic at Guy's Hospital who were not receiving insulin and were aged under 65 were invited to participate in the study. They were all patients who saw two of us (RJJ and GCV) over 14 months so that frequent attenders were not selectively recruited. The response rate was $100 \%$. These patients made a timed overnight urine collection and spent the next day in the metabolic ward, when a midstream urine sample was obtained to exclude urinary infection; none was found.

Control subjects aged 36-55 were obtained by random selection from a general practice age-sex register for Indian patients in Southall. Those known to have diabetes and one subject who was undergoing treatment for end stage renal failure were excluded, leaving 129 from an initial list of 182 , a response rate of $71 \%$.

The table shows the details of all subjects in the study. 


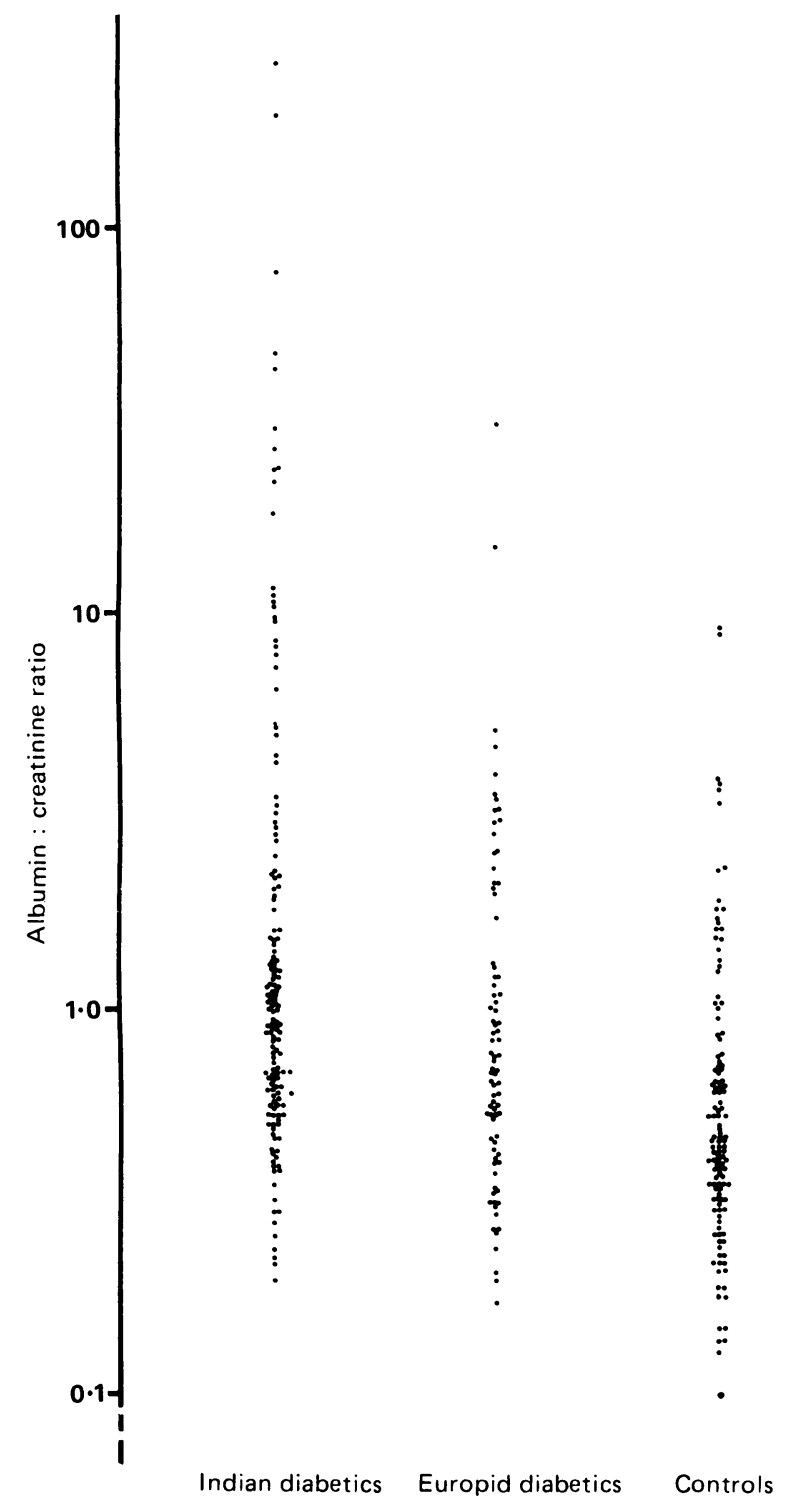

FIG 1-Distribution of albumin:creatinine ratio in three groups studied.

\section{METHODS}

The Indian diabetics and controls were sent a $25 \mathrm{ml}$ Universal container by post, collected a sample of the first urine voided in the morning, and took it to the clinic. Subjects attending the clinic at Guy's Hospital took their overnight urine collections to the metabolic ward. All patients and controls had fasted before attending the clinic or metabolic ward. Urinary albumin concentration was measured in the overnight samples and the ratio of albumin to creatinine used to assess albumin excretion. Timed overnight urine samples are perhaps preferable, but the overnight urinary albumin concentration and albumin:creatinine ratio correlate well with the albumin excretion rate $(r=0.90$ and 0.91 , respectively $) .{ }^{10}$

Urinary albumin concentration was estimated by radioimmunoassay ${ }^{11}$ and urinary creatinine concentration by the Jaffe method; and albumin:creatinine ratios were then calculated. Haemoglobin $A_{1}$ concentration in venous blood taken on arrival was estimated by the Corning agar gel electrophoresis method. All estimations were performed in the same laboratory. A proforma was completed for each patient with clinical details including the presence of known hypertension; height and weight, from which the body mass index (weight $\left(\mathrm{kg}\right.$ ) over height $(\mathrm{m})^{2}$ ) was calculated; and blood pressure. Blood pressure was measured with a Hawkesley random zero sphygmomanometer after subjects had been seated for 10 minutes. The mean of two readings from the right arm was recorded; the Korotkoff phase $\mathrm{V}$ was used to define the diastolic end point.

Statistical comparisons between groups were made with the MannWhitney test, and correlations were estimated by least squares analysis of the logarithm of the albumin:creatinine ratios, which had an almost normal distribution. Because of multiple comparisons between groups a value of $\mathrm{p}<0.01$ was considered to be significant.

The study was approved by the ethical committees of Ealing and Guy's Hospitals.

\section{Results}

Figure 1 shows individual values of albumin:creatinine ratios for all of the patients in each of the three groups. The Indian diabetics had significantly higher values than the European diabetics (Mann-Whitney z score 2.95, $\mathrm{p}=$ 0.003 ) and the Indian non-diabetics ( $\mathrm{z}$ score $3.95, \mathrm{p}<0.001$ ).

The logarithm of albumin:creatinine ratio did not correlate significantly with age, duration of diabetes, haemoglobin $A_{1}$ concentration, or body mass index in either the Indian or Europid diabetics. In the Indian diabetics an increase in albumin:creatinine ratio was significantly associated with hypertension. Thirty four Indian diabetics were being treated for hypertension, and 21 others were found to have a systolic blood pressure of more than $159 \mathrm{~mm} \mathrm{Hg}$ or a diastolic blood pressure of more than $94 \mathrm{~mm} \mathrm{Hg}$, or both. Of these 55 Indian diabetics defined as having hypertension, $24(44 \%)$ had an albumin:creatinine ratio of more than 2 , compared with $16(16 \%)$ of the 99 Indian diabetics who did not have hypertension $\left(\chi^{2}=12 \cdot 5, p<0.001\right)$. By contrast, seven $(22 \%)$ of the 31 Europid diabetics with hypertension had an albumin:creatinine ratio that exceeded 2 , compared with $10(20 \%)$ of the 51 who did not have hypertension. Even when treatment for hypertension was disregarded the logarithm of albumin:creatinine ratio showed a significant positive correlation with systolic blood pressure $(r=0.34$, $\mathrm{p}<0.001$ ) (fig 2) and diastolic blood pressure $(r=0.29, p<0.001)$ in all 154 Indian patients; these correlations were not significant in the Europid diabetics $(r=0 \cdot 20$ (fig 2$)$ and $r=0 \cdot 11$, respectively).

\section{Discussion}

This study showed that in a high proportion of Indian patients with non-insulin-dependent diabetes mellitus urinary albumin

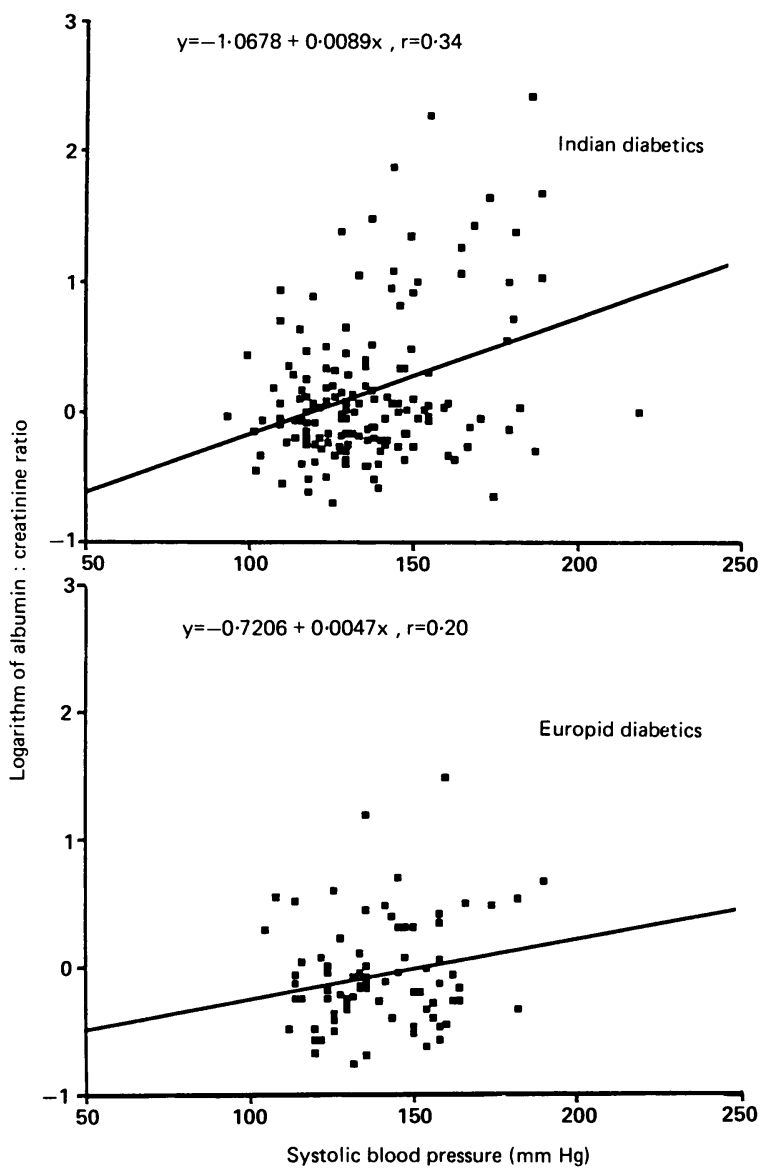

FIG 2-Correlation plot of logarithm of albumin: creatinine ratio and systolic blood pressure in Indian diabetics (top) and Europid diabetics (bottom). 
excretion is abnormally increased and significantly higher than that in comparable Europid patients. In Europid patients increased albumin excretion (microalbuminuria) indicates an increased risk of death, though the mechanisms are unknown. ${ }^{78}$ It also predicts the development of clinical proteinuria in patients with both insulin dependent $\mathrm{t}^{4-6}$ and non-insulin-dependent diabetes. ${ }^{8}$

The high prevalence of microalbuminuria in Indian diabetics is especially important because of the strikingly high prevalence of known diabetes shown in the Southall diabetes survey ${ }^{1}$ and the earlier age of diagnosis in Indians compared with Europids. The number and proportion of diabetic patients of all ethnic groups accepted for renal replacement in the United Kingdom increased appreciably from $72(5 \%)$ in 1980 to $200(11 \%)$ in $1984,{ }^{12}$ and $24 \%$ of these were patients with non-insulin-dependent diabetes mellitus. There are over 1.2 million Indians in Britain, and diabetic nephropathy in this ethnic group will probably become an increasingly important health problem.

In this study hypertension was positively associated with albumin: creatinine ratios in the Indian but not the Europid diabetics. Previous reports have given conflicting results on this point in Europids. In the Bedford study significant positive correlations were obtained between systolic blood pressure and the logarithm of albumin excretion rate in newly diagnosed diabetics. ${ }^{13} \mathrm{~A}$ low degree of positive correlation between albumin excretion rate and systolic blood pressure was also noted in subjects with fasting hyperglycaemia, known diabetics, and control subjects aged 60-74 in Denmark ${ }^{14}$ but not in Danish patients stratified by duration of diabetes and urinary albumin concentration. ${ }^{8}$ In another study albumin excretion rate was found to be increased before treatment in non-diabetic subjects with hypertension and to fall significantly after treatment. ${ }^{15}$ Such discrepancies may be real or due to differences in methodology or sample size or to sampling variation. Nevertheless, the higher proportion of patients with increased albumin:creatinine ratios among the Indian diabetics in this study cannot be ascribed to higher average blood pressure or to a greater prevalence of hypertension (table). Conceivably the kidneys of Indians may be more vulnerable to the effects of raised blood pressure or diabetes, or both.

Because of the high prevalence of diabetes in Indians and its early onset increasing morbidity and perhaps mortality from clinical nephropathy may be expected. Research should aim at assessing the efficacy of potential preventive approaches-for example, the control of blood glucose concentrations and blood pressure and perhaps dietary protein restrictions.

We acknowledge financial support from the Wellcome Trust, Guy's Hospital trustees, the Department of Health and Social Security, and Ealing Hospital Research Fund. We thank Drs S W and F Rahman for their help in recruiting the non-diabetic control subjects, and the patients and control subjects for their cooperation.

\section{References}

1 Mather HM, Keen $\mathrm{H}$. The Southall diabetes survey: prevalence of known diabetes in Asians and Europeans. Br Med F 1985;291:1081-4.

2 Nicholl CG, Levy JC, Mohan V, Rao V, Mather HM. Asian diabetes in Britain: a clinical profile. Diabetic Medicine 1986;3:257-60.

3 Samanta A, Burden AC, Feehally J, Walls J. Diabetic renal disease: differences between Asian and white patients. BrMed $\mathcal{F}$ 1986;293:366-7.

4 Viberti GC, Hill RD, Jarrett RJ, Argyropoulos A, Mahmud U, Keen H. Microalbuminuria as a predictor of clinical nephropathy in insulin-dependent diabetes mellitus. Lancet 1982;i:1430-2.

5 Parving H-H, Oxenbøll B, Svendsen A, Christiansen JS, Andersen AR. Early detection of patients at risk of developing diabetic nephropathy. A longitudinal study of urinary albumin excretion. Acta Endocrinol (Copenh) 1982;100:550-5.

6 Mogensen CE, Christensen CK. Predicting diabetic nephropathy in insulin-dependent patients. N Engl f Med 1984;311:89-93.

7 Jarrett RJ, Viberti GC, Argyropoulos A, Hill RD, Mahmud U, Murrells TJ. Microalbuminuria predicts mortality in non-insulin-dependent diabetes. Diabetic Medicine 1984;1:17-9.

8 Mogensen CE. Microalbuminuria predicts clinical proteinuria and early mortality in maturityonset diabetes. $N$ Engl f Med 1984;310:356-60.

9 Freedman BJ. Caucasian. BrMed $\mathcal{F}$ 1984;288:696-8.

10 Gatling W, Knight C, Hill RD. Screening for early diabetic nephropathy: which sample to detect microalbuminuria. Diabetic Medicine 1985;2:451-5.

11 Keen $\mathrm{H}$, Chlouverakis $\mathrm{C}$. An immunoassay method for urinary albumin at low concentrations. Lancet 1963;ii:913-4.

12 Cameron JS, Challah S. Treatment of end-stage renal failure due to diabetes in the United Kingdom, 1975-84. Lancet 1986;ii:962-6.

13 Keen H, Chlouverakis C, Fuller J, Jarrett RJ. The concomitants of raised blood sugar: studies in newly-detected hyperglycaemics. Guy's Hospital Reports 1969;118:247-54.

14 Damsgaard EM, Mogensen CE. Microalbuminuria in elderly hyperglycaemic patients and controls. Diabetic Medicine 1986;3:430-5.

15 Pedersen EB, Mogensen CE. Effect of antihypertensive treatment on urinary albumin excretion, glomerular filtration rate, and renal plasma flow in patients with essential hypertension. Scand $\mathcal{F}$ Clin Lab Invest 1976;36:231-2.

(Accepted 26 October 1987)

\section{SHORT REPORTS}

\section{Corticosteroids in treatment of disseminated tuberculosis in patient with HIV infection}

Tuberculosis in association with human immunodeficiency virus (HIV) has been well described. ${ }^{12}$ Usually it responds satisfactorily to conventional chemotherapy. ${ }^{1}$ Patients with tuberculosis who are desperately ill are often given corticosteroids as well as antituberculous chemotherapy to try to reduce the toxicity of the disease and to prevent death early in treatment. ${ }^{3}$ Corticosteroids may achieve this effect by suppressing or at least modifying cell mediated immunity.

A patient with HIV infection and disseminated tuberculosis continued to have a hectic fever and to lose weight despite treatment with quadruple chemotherapy. He showed a dramatic response to the addition of corticosteroids.

\section{Case report}

A 30 year old bisexual man was admitted with a two month history of productive cough, lethargy, and weight loss $(15 \mathrm{~kg})$. He was wasted and feverish with a temperature of $39^{\circ} \mathrm{C}$ and he had mild cervical lymphadenopathy. Blood count showed pancytopenia (haemoglobin $110 \mathrm{~g} / \mathrm{l}$, white cell count $3.0 \times 10^{9} / 1$, and platelets $129 \times 10^{9} / 1$ ). A bone marrow biopsy specimen on the same day showed numerous acid fast bacilli but no epithelioid cell granulomas. Non-reactive (non-granulomatous) disseminated tuberculosis was diagnosed and he was given quadruple chemotherapy (rifampicin, isoniazid, pyrazinamide, and ethambutol)

A chest radiograph showed some indefinite mottling in the right lower zone and an enlarged paratracheal lymph node. Sputum examination showed acid fast bacilli and later cultures were positive for Mycobacterium tuberculosis; the organisms were fully sensitive to the standard drugs. A Mantoux test with 10 tuberculin units was negative. Antibodies to HIV were detected. Serological testing for hepatitis B and syphilis gave negative results. Erythrocyte sedimentation rate was $28 \mathrm{~mm}$ in the first hour.

For six weeks the patient's condition continued to deteriorate: he remained feverish, lost weight, and grew steadily weaker (figure). At this point prednisolone $30 \mathrm{mg} /$ day was added to the regimen. His clinical condition improved almost immediately. Within three days he began to gain weight and was afebrile in 12 days. In six weeks his weight increased from $45 \mathrm{~kg}$ to $62 \mathrm{~kg}$.

At the same time the minor radiological pulmonary changes cleared completely and the haematological abnormalities reverted to normal (haemoglobin $137 \mathrm{~g} / \mathrm{l}$, white cell count $8.3 \times 10^{9} / 1$, platelets $279 \times 10^{9} / 1$, and erythrocyte sedimentation rate $5 \mathrm{~mm}$ in first hour). He was finally discharged from the hospital fit and well after five months' treatment. Steroids were gradually withdrawn before discharge, but quadruple chemotherapy was continued.

\section{Comment}

Tuberculosis, including disseminated tuberculosis, is a common feature of the acquired immune deficiency syndrome (AIDS). ${ }^{1}$ It usually responds satisfactorily to treatment even though granuloma formation is almost always impaired. A case has, however, been described of a woman with HIV disease and non-granulomatous tuberculosis who failed to respond to antituberculous chemotherapy and died. ${ }^{4}$ In our patient with non-reactive 